\title{
Research on Humanization Design of Green Building Based on Big Data
}

\author{
Niu Fang \\ School of art, Tianjin University of Technology, 300384, Tianjin, China
}

\begin{abstract}
Now people life is becoming better and better, the demand for life also gradually increases. Based on the current situation of China's rising economic strength and large population base, the demand for construction has been expanded. Therefore, the construction industry has brought a lot of pollution and energy consumption. The solution to this problem is to insist on sustainable development, namely green building design. To carry on green design and better safeguard the purpose of the green design and humanized service, based on the powerful weapon Internet, we bring China's powerful weapon for China developed Internet, which is big data.
\end{abstract}

\section{Overview of green buildings and big data}

The concept of green building design originates from the architect Paola Soleri, which is the effective utilization of resources and meeting the needs of ecological development and sustainable development. The simple explanation is saving energy, saving water, reducing the floor area, reducing the material consumption, and minimizing the pollution and destruction of the environment. It dedicates to building a comfortable human habitation environment and in harmony development with nature. President Xi Jinping said: " Lucid waters and lush mountains are invaluable assets. " The connotation of green building includes: first, green building emphasizes the health, comfort and safety of life. The second is that green buildings should apply to all buildings. Green buildings are not just our homes, but also include all building systems. The third, the green building from building materials production, construction planning, design, construction, operation and maintenance and dismantling, recycling, the generation of construction to dismantling the entire life course, should embody the efficient use of resources, including energy, land, water and materials. Finally, the impact of green building on the environment should be minimized.

The big data is the information data aggregation caught, managed and processed by using normal software tools. It can calculate a person's hobby, so as to conduct personal services. The essence of Green building design is to enable people to live in harmony with nature. Meanwhile, it will try to enhance people's living standard. The focus of this research is how to protect the environment and improve living quality of people at the same time.

\section{The construction industry's current situation and the intelligent development foreground}

The 2017 revised edition of the World Population outlook report, was released recently by the United Nations. It shows that the world's population is expected to reach nearly 10 billion in 2050, and the size of the urban population will be accompanied by a further expansion of the pace of urbanization, up to the current one-fold, and by 2050 about $75 \%$ of the population living in urban areas.

In order to cope with the population pressure brought about by the development of urbanization, about 1000 new kinds of construction facilities need to be added every day worldwide. In addition, the global investment in energy, water Conservancy, telecommunications, transportation and other infrastructure will cost about $\$ 3.3$ trillion a year from now to 2030 . Therefore, the construction industry not only faces unprecedented development opportunities, but also plays an important role in leading the sustainable development and creating a better future. For human society, a better future also means that when the global population reaches the 10 billion in 2050, the construction industry will be able to provide the building facilities that can meet the needs and resources of the large population through the intelligent and sustainable development of the architectural design, so that people can be obtain the necessary, comfortable life, and live happily in the Earth's limited resources.

But the reality is that the construction industry is not yet fully prepared to meet this opportunity and challenge. For a long time, whatever the technical level or the model level, the construction industry made of low profit,

* Corresponding author: ${ }^{\text {3 350244152@qq.com }}$ 
high risk, extensive, divergent management still exists. Many projects at all stages of the life cycle, generally are applicable to the geometry, tables and text drawing of physical drawings, the design of the "wisdom" is largely hidden. At the same time, the construction industry still has the problem of insufficient investment in technology. A recent statistic shows that the number of digital inputs in the construction industry is only about $1.2 \%$ of the total output, compared with $3.3 \%$ in manufacturing. From the perspective of digital input, the construction industry in science and technology investment is higher than the agricultural and hunting industry, so the construction industry can embark on a more intelligent, digital development path.

According to McKinsey's latest research, if the construction industry can fully digitize the entire life cycle of the project, the annual cost savings will be as high as $\$ 1.2$ trillion, accounting for $10 \%$ of the current global construction market value. And as a pillar industry that ties the nation's livelihood, the construction industry, with 220 million of its employees, contributes more than $10 \%$ of global GDP, so this 1.2 trillion represents $1-2 \%$ of global GDP. Therefore, the development of digital applications in the construction industry has great potential and will inevitably bring about subversive changes to the whole industry.

\section{The Internet big data and other digital technology to guide the construction Industry Intelligence, green development}

In recent years, some other digital technology has been gradually applied to the construction industry, to help the construction industry to open the intelligent, sustainable development of the New World, and with the Internet to promote the industry's high-speed development into the fature of green, synergy, intelligence.

Artificial Intelligence: The application of artificial intelligence has been quite hot in many industries in recent years. and as to the construction industry particularly, the application of artificial intelligence is to learn advanced technology, foresee the future, create new designs by using machines, and avoid past mistakes, provide a greener building environment. For example, in the design process of the Autodesk Toronto Office, the project team has done research on multi-parameter optimization for the overall layout of the office, including the walking distance needed for collaborative communication between teams, visual requirements and sound disturbances in each location, natural lighting, lighting and acoustic analysis, and outdoor landscape analysis. Finally completed the office not only in style to a great extent to meet the staff's preferences, but also in the comfort, anti-jamming and other aspects of the staff to bring about an excellent office experience.

Digital Synergy: With the rise of virtual reality technology, VR and AR technology are being used more and more in freauently the design and construction of construction engineering projects. For example, in Autodesk Live, professional designers can quickly and easily transform the design model into VR data, and integrate with mainstream VR devices such as HTC VIVE, Microsoft HoloLens, etc. to realize the immersive experience of design applications. This will help designers to understand, explore, optimize and share their various solutions, and perform real-time visualization of construction site management.

Internet of things and big data analysis technology: Finally, it is now more and more convenient, can be loaded into anything on the sensor. Sensors and GPS integration allow us to accurately locate the target, timely access to information, and loaded into the design model, real-time data analysis, accurate understanding of the construction site, the performance of construction facilities, so as to help us to find and solve problems in a timely manner.

\section{The humanized embodiment in green building design}

The basic purpose of building design is to serve people, and green building design is no exception. In green building design, humanized design is emphasized to make people's life convenient and it can also increase people's love for environment. The Kindergarten in Guastalla designed by Mario Cucinella, a humanized design master, is very impressive. The Italian Kindergarten in Guastalla was destroyed in earthquake and his architectural firm won the rights to build it. As a kindergarten, the project created an all-around educational environment in addition to a good grasp of the space. In doing so, it can promote the interaction between the children and the environment. It helps to cultivate children's passion for green living habits, hence to enhance living quality and increase children's passion for environment. It greatly integrates the indoor and outdoor space from the division of teaching section to the choice of building materials. The kindergarten's building elements, including indoor form, space organization, the choice of materials and senses organs related to light, color, sound, and touch, are all taken into consideration. By the design practice of green building, Mario Cucinella hopes people to realize that if building can live in harmony with the surroundings, people can enhance their living quality without consuming too much resources and energy.

In order to design this kind of green building in China, we should rely on the analysis based on the big data of the internet. The internet big data can analyse much faster the real situation of the area and the local people, and provide a corresponding design.

\section{The main points of humanized Green building design for designers}

Designers have to carry out green building design, from the design of drawings, comprehensive implementation of the concept of green energy conservation, grasping the latest technology, so that to combine green design and intelligence, to meet the consumer, personalized, 
standardized, refined, convenient and multi-angle of the new requirements of the design.

In the intelligent building design, it is necessary to ensure the advanced nature of its automatic control system, so that intelligent buildings play its due effect. For its internal network communication and other facilities need to ensure that it has good patency, so that its own quality of service and efficiency of construction can, get perfect improvement, guarantee people's life fast rhythm and safety problem.

In the past, the architectural design, the broad and the atmosphere, and the building itself will be larger, more open, so that the consumption of resources will increase and management applications will be affected. Therefore, in the architectural design, the full and effective use of space resources, reasonable arrangement of various design methods, improve space utilization, achieve intensification, pay attention to energy consumption, effectively improve the actual level of architectural design, so that the building can be more humane and closely integrated.

\section{How to combine green architecture, big data and humanization}

Green building refers to providing people with healthy, comfortable and safe living, the space of work and living, meanwhile, in the whole life cycle of the building (that is, building planning, design, production and transportation of building materials, construction, maintenance to demolition, construction of raw materials reuses the entire process) to achieve efficient use of resources, the minimum impact on the environment of buildings. The green building under the Internet Big Data technology, by way of saving the energy and using the resources effectively, construct the safe, healthy, high efficiency and comfortable environment space under the low environment load, and it is the new building pattern of the symbiosis and sustainable development of people, environment and architecture. Construction enterprises should establish the belief of green architectural design with big data service and carry out this initiative.

The use of Internet big data is to guide the sustainable development of green buildings to guide the construction of green design, new products, green building materials, new materials, new technology Internet, the implementation of cleaner production, cleaner production requirements from the product design, to select raw materials, process and equipment and waste utilization. All aspects of operation management, through continuous technological innovation, improve the utilization of resources, from the source to prevent pollution. Application of big data analysis technology, select renewable raw materials, recyclable raw materials can be recycled after the use of materials, and the implementation of cleaning operations. Use IT technology to visualize and compare green architectural design to people's supervision. Through continuous improvement of management and technological progress, improve resource utilization, reduce environmental and human hazards.
The construction enterprises take harmless measures, application of big data technology, use green building materials; the future construction process will be under strict supervision of Internet. The construction manufacturers, and construction sites, construction supervision, are "seamlessly" connected, in order for the entire construction of green management system to achieve zero inventory, low pollution, high quality and low cost. The construction enterprise management personnel should use the Internet technology, increase the green construction whole process populace participation, the interaction and the visualization, strengthen the poisonous harmful building solid waste management, the poisonous substance, the insoluble material effective classification, enlarges the construction waste supervision dynamics, carries on the science effective processing. They apply the Internet big data technology to display ISO14000 Environmental management standards certification. Through the establishment and operation of environmental management system, the environmental benefits, economic benefits and social benefits have been achieved. such as reducing the energy consumption, material, reduce production costs, reducing environmental pollution, establishing a good image of enterprises, and improving the competitiveness of enterprises.

\section{Conclusion}

Looking into the future, the green building market has a wide prospect and great potential. At the same time, in the face of the current situation of serious energy shortage, the development of green building market, the implementation of green design concept is imperative. Therefore, designing as a means to shape the world, leading the green development of construction industry, will increasingly participate in all aspects of green construction, to promote the construction industry's green, healthy development. The use of new era of information technology and digital technology to assist designers in green architectural design, can ensure the promotion of corporate green awareness, and greener, environmentally friendly, sustainable building environment for the people at, so as to truly achieve the overall social green development goals.

\section{References}

1. Ye Tinghong. Analysis on the design strategy of endowment architecture based on green building concept [J]. Engineering technology: full-text version, 2017 (2) : 5.

2. Li Yanqi. Analysis of green building design based on full life cycle [J]. Engineering technology: 35.

3. Chen Peng, mille. Analysis on the key points of green building design $[\mathrm{J}]$. Residential and real estate, 2016 (18). 
4. Wang Congcong. Analysis of key points based on green building design $[\mathrm{J}]$. Architectural engineering technology and design, 2014 (29).

5. Cai Quedan. Analysis on the technological evolution and design of intelligent building in the Internet of things [J]. Modern architecture electric, 2013(S1).

6. Wang Jing, Gan Lu, Li Hongwang. Quedan. The integrated intelligent building that can breathe -- the highlight of the design of the integrated house design of a substation [J]. Industrial building, 2013(S1)

7. Guo Xiujuan, Xu Jinqiu. Design and analysis of integrated wiring system in intelligent building $[\mathrm{J}]$. Journal of jilin institute of architectural engineering, 2013(05)

8. Wei Yanwu. Natural architecture [M]. Jinan: shandong people's publishing house, 2010.

9. Qiu Jize. Living in a good house [M]. Hangzhou: zhejiang university press, 2011.

10. Du hui. On the humanized design of future concept architecture [J]. Technology wind, 2016. 